\title{
Pudding Dosage Form
}

National Cancer Institute

\section{Source}

National Cancer Institute. Pudding Dosage Form. NCI Thesaurus. Code C68972.

A semi-solid, having a relatively thick consistency, intended for oral administration to facilitate ease of swallowing. 